\title{
Paraelastic interstitials in molybdenum $\left({ }^{*}\right)(* *)$
}

\author{
B. Beuneu and Y. Quéré \\ Section d'Etudes des Solides Irradiés, C.E.N., B.P. n $^{\circ}$ 6, 92260 Fontenay aux Roses, France
}

(Reçu le 10 juillet 1981, accepté le 15 septembre 1981)

\begin{abstract}
Résumé. - La relaxation paraélastique d'un défaut ponctuel de nature interstitielle a été observée entre 22 et $25 \mathrm{~K}$ dans du molybdène irradié aux électrons à $\simeq 20 \mathrm{~K}$. La fréquence $\left(9 \times 10^{11 \pm 0,6} \mathrm{~s}^{-1}\right)$ et l'énergie $(72 \pm 3 \mathrm{meV})$ de cette relaxation ont été mesurées.

Le défaut présente une résistivité plus grande lorsqu'il est parallèle au courant électrique que lorsqu'il est transverse.
\end{abstract}

Abstract. - The paraelastic relaxation of a point defect of interstitial nature has been observed between 22 and $25 \mathrm{~K}$ in low temperature electron-irradiated molybdenum. The frequency $\left(9 \times 10^{11 \pm 0.6} \mathrm{~s}^{-1}\right)$ and the energy $(72 \pm 3 \mathrm{meV})$ of this relaxation have been measured.

The resistivity of the defect is higher when it is parallel to the electric current than when it is transverse.

The concept of paraelasticity was introduced twenty years ago by Känzig [1] to describe the reorientation of oxygen molecules along a $\langle 110\rangle$ direction in some f.c.c. alkali halides under a uniaxial elastic stress. In these experiments, the polarization obeys a classical Brillouin law.

We describe thereafter an experiment where the stress-induced reorientation concerns a point defect created by irradiation in molybdenum.

1. Experiment. - The sample is a single crystal plate of molybdenum (parallel to $\{100\}$ planes) with a length $\sim 17 \mathrm{~mm}$ (parallel to [110]), $\sim 0.6 \mathrm{~mm}$ wide and $\sim 45 \mu \mathrm{m}$ thick.

It is set into a miniaturized tensile testing machine, derived from that described by Conte and Von Stebut [2], which allows simultaneous measurements of stress and strain of the sample which is here uniaxially stressed along the principal direction (i.e. [110]). The machine is introduced into a liquid hydrogen bath, in front of the electron beam of the Van de Graaff accelerator of our laboratory. The regulation of the hydrogen pressure above the bath allows a temperature stability of $\pm 0.01 \mathrm{~K}$ between $16 \mathrm{~K}$ and $25 \mathrm{~K}$ [3]. The electrical resistance of the single crystal can be measured automatically [4].

The single crystal, with an initial resistivity

$\left(^{*}\right)$ La version française de cet article a été proposée pour publication aux Comptes Rendus de l'Académie des Sciences.

$\left({ }^{* *}\right)$ We dedicate this paper to our Soviet colleagues Y. Orlov and V. Brailowsky. $\rho_{0}=4 \mathrm{n} \Omega . \mathrm{cm}$ at $4 \mathrm{~K}(\rho 300 / \rho 4=1200)$ is irradiated without stress at temperatures of about $20.1 \mathrm{~K}$ with $1.5 \mathrm{MeV}$ electrons, up to an increase of resistivity $\Delta \rho_{0}=245 \mathrm{n} \Omega . \mathrm{cm}$ corresponding to a Frenkel pair concentration of about $1.9 \times 10^{-4}$ [5].

It is then heated up to a temperature of about $30 \mathrm{~K}$ for 20 minutes. This results in eliminating the most unstable Frenkel pairs. After this treatment, which leaves a remaining excess of resistivity

$$
\Delta \rho_{0}^{\prime}=206 \mathrm{n} \Omega . \mathrm{cm}
$$

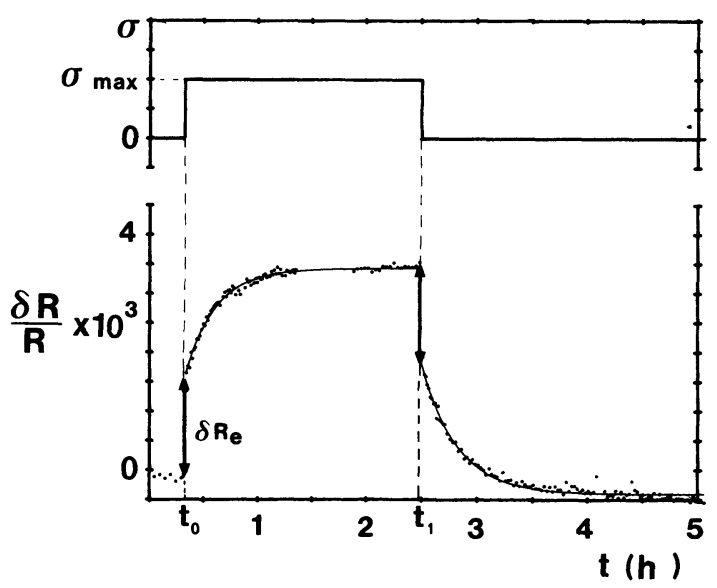

Fig. 1. - Time dependence of electrical resistance of electronirradiated molybdenum, during anneal at $T_{\mathrm{R}}=23.7 \mathrm{~K}$, when a uniaxial stress $\sigma=\sigma_{\max }$ is introduced (at time $t_{0}$ ) or removed (at time $\left.t_{1}\right) . \delta R_{\mathrm{e}}=$ elastoresistance. Full line $=$ exponential curve fitted to the experimental results. $t=$ time in hours. 
(i.e. $84 \%$ of the initial $\Delta \rho_{0}$ ), no other recovery will take place during the further anneals below $28 \mathrm{~K}$ which we describe hereunder.

The sample is then submitted to a series of isothermal treatments at temperatures $T_{\mathrm{R}}$ between $22.5 \mathrm{~K}$ and $24.8 \mathrm{~K}$, under a uniaxial stress. More precisely (see Fig. 1), at each temperature $T_{\mathrm{R}}$, we suddenly apply a stress $\sigma=\sigma_{\max }$ (just below the yield point), at time $t_{0}$. At a further time $t_{1}$, we unload the sample very quickly, at the same temperature $T_{\mathrm{R}}$. The electrical resistance of the sample is measured as a function of time during all operations.

2. Results. - A typical isothermal experiment is shown as an example on figure 1 .

We start $\left(t<t_{0}\right)$ from an unloaded state : the resistivity is constant. At time $t_{0}$, we observe a sudden increase of the resistance $\delta R_{\mathrm{e}}$. This variation is due to the superposition of two effects : a change in the dimensions of the sample, and an elastoresistive term $\delta \rho_{\mathrm{e}}$, which mainly represents the elastoresistivity of the radiation-induced point defects [6-8]. After $t_{0}$ we observe a further increase of the resistivity $\delta \rho_{\mathrm{p}}(t)$ which tends to a saturation value $\delta \rho_{\mathrm{p}}^{\infty}$. When we unload the sample at time $t_{1}$, we observe two successive decreases of the resistivity : $\delta \rho_{\mathrm{e}}^{\prime}=-\delta \rho_{\mathrm{e}}$ and $\delta \rho_{\mathrm{p}}^{\prime}(t)=-\delta \rho_{\mathrm{p}}(t)$.

We can sum up the main results as follows :

i) The quantities $\delta R_{\mathrm{e}}$ do not depend on $T_{\mathrm{R}}$. They are proportional to $\sigma$ and vary linearly with the defect concentration $[6,8]$.

ii) The resistivities $\delta \rho_{\mathrm{p}}$ (or $\delta \rho_{\mathrm{p}}^{\prime}$ ) vary exponentially with time $t$ (see Fig. 1), and in a reversible way : $\delta \rho_{\mathrm{p}}\left(t-t_{0}\right) \equiv-\delta \rho_{\mathrm{p}}^{\prime}\left(t-t_{1}\right)$.

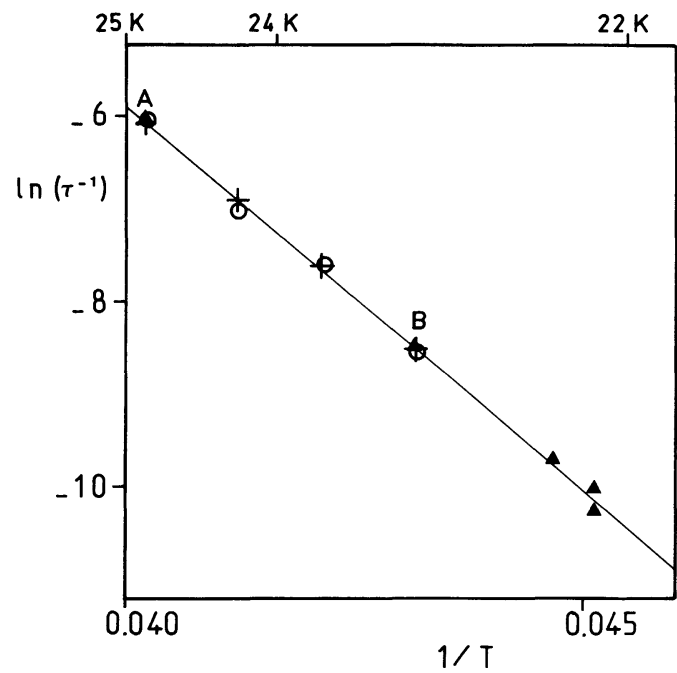

Fig. 2. - Arrhenius plot of the characteristic time $\tau$ (eq. (1)). $\tau$ (here in seconds) is obtained from exponentials (like that of figure 1) fitted to the experimental results. Crosses and circles correspond respectively to parts $\sigma=\sigma_{\mathrm{M}}$ and $\sigma=0$ of relaxation curves of a first experiment. Triangles correspond to a second experiment. At A and B, the three symbols are superimposed. iii) The effect is thermally activated. The analysis of the characteristic times $\tau$ (see Fig. 2) leads to :

$$
\tau^{-1}=\left(\tau_{0}\right)^{-1} \exp (-E / k T)
$$

where :

$\left(\tau_{0}\right)^{-1}=9 \times 10^{(11 \pm 0.6)} \mathrm{s}^{-1}$ and $E=(72 \pm 3) \mathrm{meV}$.

iv) The amplitude of the effect $\left(\delta \rho_{\mathrm{p}}^{\infty}\right)$ is proportional to $\sigma$.

v) In some cases, a second exponential term, with a very long characteristic time, is superimposed on the main one described in ii) and iii). It can be neglected in first analysis.

vi) The whole effect disappears after an anneal at $37 \mathrm{~K}$.

3. Discussion. - We will not discuss point i) which is typical of elastoresistivity [6-8].

Points ii) to iv) clearly show that a radiation induced point defect relaxes under stress without annealing out.

The energy of the electrons is less than twice the threshold energy (0.84 MeV for molybdenum [5]), so that only single vacancies and interstitials are created, associated in pairs, the closest - or the most unstable - of which have been eliminated during the initial anneal (see $\S 1$ ). Taking into account the measured energy and frequency (see iii)), the most likely phenomenon taking place is a paraelastic reorientation of split interstitials between two $\langle 110\rangle$ directions.

Similar effects have been observed by means of elastic after-effect and internal friction measurements on molybdenum samples irradiated with neutrons [10] or electrons [11] with comparable activation energies.

In our case, the uniaxial stress is produced along [110], and it is clear that the six-fold degenerate system of energies of the six $\langle 110\rangle$ configurations splits into a low level $E^{-}$(the [110] configuration), a high level $E^{+}([1 \overline{1} 0])$, and four equal intermediate levels $E_{0}([011],[01 \overline{1}],[101]$ and [101]).

When $E^{+}-E^{-}$is small compared to $k T$ (and proportional to the stress, to first order), it is easy to show that the evolution of the initially unpolarized system results in an overcrowding of level $E^{-}$, at the expense of the level $E^{+}$, through the reservoir $E_{0}$; and that the resulting polarization varies quasiexponentially with time, as observed experimentally (point ii)).

This polarization gives rise to an increase of the resistivity, a slightly unexpected result. This indicates that the resistivity of the split interstitial is higher when the dumbbell is parallel to the electrical current than when it is perpendicular to it.

Acknowledgments. - It is a pleasure to thank P. Lucasson - who gave us the single crystal used here - and F. Maury for useful discussions. 


\section{References}

[1] KÄnzIG, W., Phys. Rev. Lett. 7 (1961) 304.

[2] Conte, R. R., Von Stebut, J., Revue Phys. Appl. 4 (1969) 770.

[3] Dural, J., Thèse Poitiers, Rapport CEA-R-5091 (1981).

[4] Bouffard, S., Rapport CEA-R-5015 (1979).

[5] Maury, F., Vajda, P., Biget, M., Lucasson, A., Lucasson, P., Radiat. Eff. 25 (1975) 175.

[6] Von Stebut, J., Thèse, Orsay (1973), Rapport CEA-R-4558 (1973).

[7] Delsarte, G., J. Physique 36 (1975) 1261.
[8] Beuneu, B., J. Physique-Lett. 40 (1979) L-547.

[9] Johnson, R. A., Phys. Rev. 134 (1964) A 1329.

EHRHART, P., In Fundam. aspects of rad. dam. in metals, M. T. Robinson and F. W. Young Eds., ERDA report conf. 751006 (1976), p. 302.

[10] Mizubayashi and Oxuda, S., Radiat. Eff. 33 (1977) 221.

[11] Jacques, H., Robrock, K. H., Proceedings of ICIFUAS 7, 6-9 July 1981 (Lausanne). 